\title{
Sistem Informasi Program Persediaan Barang (Studi Kasus Pada TB. Harapan Mulya II)
}

\author{
Nila Hardi ${ }^{1, *}$, Henny Leidiyana ${ }^{2}$ \\ * Korespondensi: e-mail: henny.hnl@bsi.ac.id
}

\begin{abstract}
1 Program Studi Rekayasa Perangkat Lunak, Universitas Bina Sarana Informatika, Jl. Kramat Raya No.98, Daerah Khusus Ibukota Jakarta, e-mail: nila.nad@bsi.ac.id 2 Program Studi Sistem Informasi, Universitas Bina Sarana Informatika, Jl. Kramat Raya No.98, Daerah Khusus Ibukota Jakarta, e-mail: henny.hnl@bsi.ac.id
\end{abstract}

Submitted: 6 Oktober 2020

Revised: 27 Oktober 2020

Accepted: 10 November 2020

Published: $\mathbf{3 0}$ November 2020

\begin{abstract}
A computer is a tool created to facilitate human work. In this era of information technology has achieved very good progress from the manufacture of hardware and software. TB. Harapan Mulya II is a trading company engaged in the sale of building materials. System on TB. Harapan Mulya II uses a system that is still manual, starting from recording user data, goods, customers, suppliers, incoming goods, items out, goods orders and the process of making reports relating to inventory. Allows the occurrence of errors in managing inventory, so that it can cause inaccurate inventory data. The research method used to compile this thesis uses the method of software development (waterfall) and data collection techniques include: Observation, interviews and literature study. By making the design of this program is the best solution to overcome the problems that exist today, as well as with computerized inventory of goods in this company so that all activities undertaken are better than the previous system.
\end{abstract}

Keywords: Inventory, Program, Design

\section{Abstrak}

Komputer merupakan alat yang diciptakan untuk mempermudah pekerjaan manusia. Pada era sekarang ini teknologi informasi sudah mencapai kemajuan yang sangat baik dari pembuatan hardware maupun software nya. TB. Harapan Mulya II merupakan perusahaan dagang yang bergerak dibidang penjualan bahan bangunan. Sistem pada TB. Harapan Mulya II menggunakan sistem yang masih manual, mulai dari pencatatan data user, barang, customer, supplier, barang masuk, barang keluar, order barang dan proses pembuatan laporan yang berhubungan dengan persediaan barang. Memungkinkan terjadinya kesalahan dalam mengelola persediaan barang, sehingga dapat menyebabkan ketidak akuratan data persediaan yang ada. Metode penelitian yang digunakan untuk menyusun tugas akhir ini menggunakan metode pengembangan perangkat lunak (waterfall) dan teknik pengumpulan datanya meliputi: Observasi, wawancara dan studi pustaka. Dengan pembuatan perancangan program ini merupakan soulsi yang terbaik untuk mengatasi permasalahan yang ada saat ini, serta dengan terkomputerisasinya persediaan barang di perusahaan ini sehingga semua kegiatan yang dijalani menjadi lebih baik lagi dari sistem terdahulu

Kata kunci: Persediaan, Perancangan, Program 


\section{Pendahuluan}

Aktifitas di perusahaan saat ini banyak menggunakan sistem yang terkomputerisasi untuk memudahkan karyawannya dalam mengelola data, termasuk di dalamnya yaitu pada perusahaan yang bergerak dibidang perdagangan. Perusahaan dagang menggunakan sistem terkomputerisasi tersebut guna meningkatkan keefisiensian dan keakuratan dalam pengolahan data,salah satu penerapannya yaitu dalam pengolahan data persediaan barang. Persediaan barang adalah barang-barang yang disimpan untuk digunakan atau dijual pada masa yang akan datang. Persediaan terdiri dari spersediaan bahan baku, persediaan bahan setengah jadi dan persediaan barang jadi. Pengelolaan persediaan barang yang baik tidak hanya di perlukan oleh perusahaan dagang yang besar, melainkan perusahaan dagang menengah bahkan sekedar toko pun memerlukannya (Rahayu et al., 2016).

TB. Harapan Mulya II adalah usaha yang bergerak di bidang perdagangan yang menjual bahan bangunan. Proses pengelolaan data persediaan barang pada TB. Harapan Mulya II masih tergolong manual. Persediaan barang adalah barang-barang yang disimpan untuk digunakan atau dijual pada masa yang akan datang. Persediaan terdiri dari spersediaan bahan baku, persediaan bahan setengah jadi dan persediaan barang jadi (Rahayu et al., 2016).

Kegiatan bisnis masih manual, pengolahan data yang berhubungan sistem persediaan barang baik itu data barang, data supplier, data customer, data persediaan barang, data transaksi dan laporan transakski masih di catat di kertas serta penyimpanan data-data diatas masih belum baik sehingga kemungkinan berkas rusak, tercampur bahkan hilang sangat besar (Rosidin \& Lubis, 2017).

Begitupun yang terjadi pada TB. Harapan Mulya ini, untuk mengetahui stok barang yang ada di gudang, staff gudang masih harus menghitung secara langsung dan itu memakan waktu yang cukup lama sehingga tidak efisien dan kemungkinan adanya kesalahan perhitunganpun masih sangat tinggi . Pembuatan laporan untuk persediaan barangnya pun masih di lakukan secara manual sehingga sangat mudah adanya kelicikan staff gudang dalam pembuatan laporan tersebut.

Dari permasalahan tersebut, maka dalam penanganannya diperlukan akses untuk mempermudah perhitungan persediaan barang dan juga dapat meningkatkan ke akuratan laporan persediaan barang pada TB. Harapan Mulya II yaitu dengan membuat aplikasi menggunakan bahasa pemrograman Java. Java adalah bahasa pemrograman yang powerfull dan serbaguna untuk pengembangan perangkat lunak yang berjalan di perangkat seluler, perangkat desktop, dan server (Enterprise, 2017). Java adalah sebuah teknologi yang di perkenalkan oleh Sun Microsystems pada pertengahan tahun 1991 yang di pimpin oleh Patrick Naughton dan James Gosling. Mulanya dikenal dengan nama "oak" kemudian diganti dengan nama "java" karena sebelumnya telah ada bahasa yang bernama "oak" (Hariyanto, 2014). Aplikasi untuk membuat program menggunakan Netbeans. (Haqi, 2017) mengemukakan bahwa, "The Netbeans adalah sebuah lingkungan pengembangan sebuah kakas untuk pemrogram menulis, kompilasi, mencari kesalahan, dan menyebarkan program". 
Aplikasi ini dibuat menggunakan database. Basis Data (database) adalah kumpulan data berelasi yang disusun, diorganisasikan dan disimpan secara sistematik dalam media simpan computer mengacu kepada metode-metode tertentu sedemikian rupa sehingga dapat diakses secara cepat dan mudah menggunakan program/aplikasi komputer untuk memperoleh data dari basis data tersebut (Rosidin \& Lubis, 2017). Untuk aplikasi database digunakan MySQL. MySQL adalah sebuah perangkat lunak sistem manajemen basis data SQL (Database Management system) atau DBMS yang multithread, multiuser, dengan sekitar 6 juta instalasi di seluruh dunia (Haqi, 2017).

Keluaran aplikasi ini adalah laporan yang bibuat menggunakan aplikasi iReport. iReport adalah utilitas (perkakas) pelaporan yang di kembangkan di lingkungan java guna membantu user dan develover (pengembang/programmer) mendesain laporan secara visual (Haqi, 2017).

\section{Metode Penelitian}

Metode yang digunakan pada pengembangan perangkat lunak ini menggunakan model waterfall (Sukamto \& Shalahuddin, 2015) yang terbagi menjadi lima tahapan, yaitu analisa kebutuhan perangkat lunak, desain, pembuatan kode program, pengujian dan pendukung pemeliharaan.

Pada tahap analisa kebutuhan perangkat lunak hasil dari analisa kebutuhan user antara lain, user dapat melakukan login. User dapat mengelola data master yaitu barang, supplier, customer dan data user itu sendiri serta dapat mengelola data transaksi barang masuk, transaksi order barang, transaksi barang keluar dan juga melihat.

Berdasarkan tahapan analisa kebutuhan, maka di perlukan desain database dengan tabel user, tabel barang, tabel supplier, tabel customer, tabel transaksi barang masuk, tabel transaksi order, tabel transaksi barang keluar. sedangkan interface yang di butuhkan antar lain form login, form data user, form data barang, form data supplier, form data customer, form transaksi barang masuk, form transaksi order barang, form transaksi barang keluar dan cetak laporan.

Setelah melalui tahap desain, pembuatan kode program menggunakan bahasa pemrograman dengan Java Netbeans IDE 8.1 dan SQL dengan estimasi waktu 2 (dua) bulan. Setelah program di buat maka di lakukan tahap pengujian dengan metode Black Box Testing dengan estimasi waktu 2 (dua) minggu supaya program sesuai dengan kebutuhan user. Setelah semua tahapan selesai, maka tahapan ini adalah tahapan pendukung atau pemeliharaan seperti pembaharuan informasi, persiapan software dan pelatihan.

Sedangkan teknik pengumpulan data yang digunakan adalah pengamatan (observasi), wawancara (interview) dan studi Pustaka (library research). Observasi dilakukan dengan melakukan pengamatan secara langsung cara pengelolaan data persediaan barang yang ada di TB. Harapan Mulya dari mulai pencatatan data barang, transaksi barang masuk, transaksi barang keluar hingga pembuatan laporan. Wawancara dilakukan dengan metode tanya jawab kepada Bapak H. Mas'ud selaku pemilik TB. Harapan Mulya II tentang proses proses 
pengelolaan data barang, pengelolaan data transaksi barang masuk, pengelolaan data transaksi barang keluar serta pengelolaan data laporan yang ada di toko tersebut. Studi pustaka dengan mencari referensi dari berbagai buku, internet dan jurnal sehingga dapat membantu dalam penulisan ini.

\section{Hasil dan Pembahasan}

Untuk menghasilkan aplikasi yang sesuai dengan kebutuhan maka perlu dilakukan analisa siapa saja dan apa saja yang dibutuhkan oleh pengguna. Di sini analisa kebutuhan dibagi menjadi tiga yaitu kebutuhan administrator, pengguna, dan kebutuhan sistem.

A. Kebutuhan administrator, yaitu (1) Administrator dapat login untuk dapat mengakses aplikasi, (2) Mengganti password login, (3) Mengelola data user, (4) Mengelola data barang, (5) Mengelola data customer, (6) Mengelola data supplier, (7) Melakukan penginputan transaksi barang masuk, (8) Melakukan penginputan transaksi barang keluar, (9) Melakukan transaksi order barang, (10) Melihat laporan data barang, (11) Melihat data barang yang masuk dalam stok minimal, (12) Melihat laporan data customer, (13) Melihat laporan data supplier (14) Melihat laporan data transaksi barang masuk, (Melihat laporan data transaksi barang keluar

a. Melihat laporan data transaksi order barang

B. Kebutuhan staff pengguna, yaitu (1) Staff pengguna dapat login untuk dapat mengakses aplikasi, (2) Mengganti password login Mengelola data customer, (3) Melakukan penginputan transaksi barang masuk, (4) Melakukan penginputan transaksi barang keluar, (5) Melakukan transaksi order barang, (6) Melihat laporan data barang, (7) Melihat data barang yang masuk dalam stok minimal, (8) Melihat laporan data customer, (9) Melihat laporan data supplier, (10) Melihat laporan data transaksi barang masuk, (11) Melihat laporan data transaksi barang keluar, (12) Melihat laporan data transaksi order barang

C. Kebutuhan sistem, yaitu (1) Pengguna harus melakukan login terlebih dahulu untuk dapat mengakses program ini dengan memasukan username dan password agar privasi masingmasing pengguna tetap terjaga keamanannya. (2) Pengguna harus melakukan logout setelah selesai menggunakan program agar ada pihak lain yang menyalah gunakan akun pengguna tersebut. (3) Sistem melakukan kalkulasi stok persediaan barang.

Sebelum pembuatan basis data, dilakukan perancangan basis data menggunakan Entity Relatioship Diagram (ERD). Terdapat tujuh entitas beserta relasinya, entitas tersebut terdiri dari user, customer, supplier, barang, order barang, transaksi masuk dan transaksi keluar. Lebih jelasnya ERD dari aplikasi terlihat pada Gambar 2. 


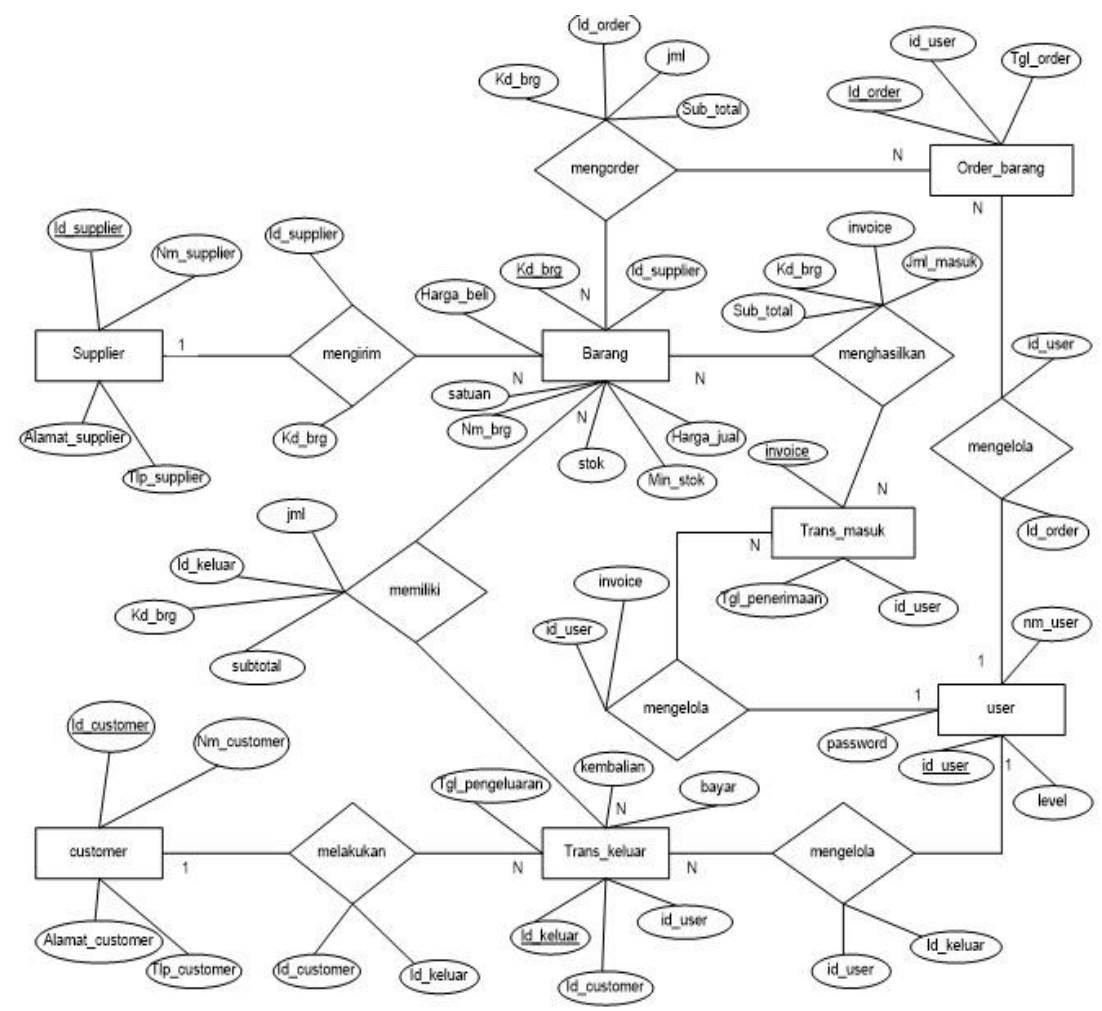

Sumber: Hasil Penelitian (2020)

Gambar 1. Entity Relatioship Diagram (ERD)

Perancangan basis data juga menggunakan Logical Structure Record (LRS) seperti pada Gambar 2 yang terdiri dari tujuh entitas beserta atribut-atributnya.

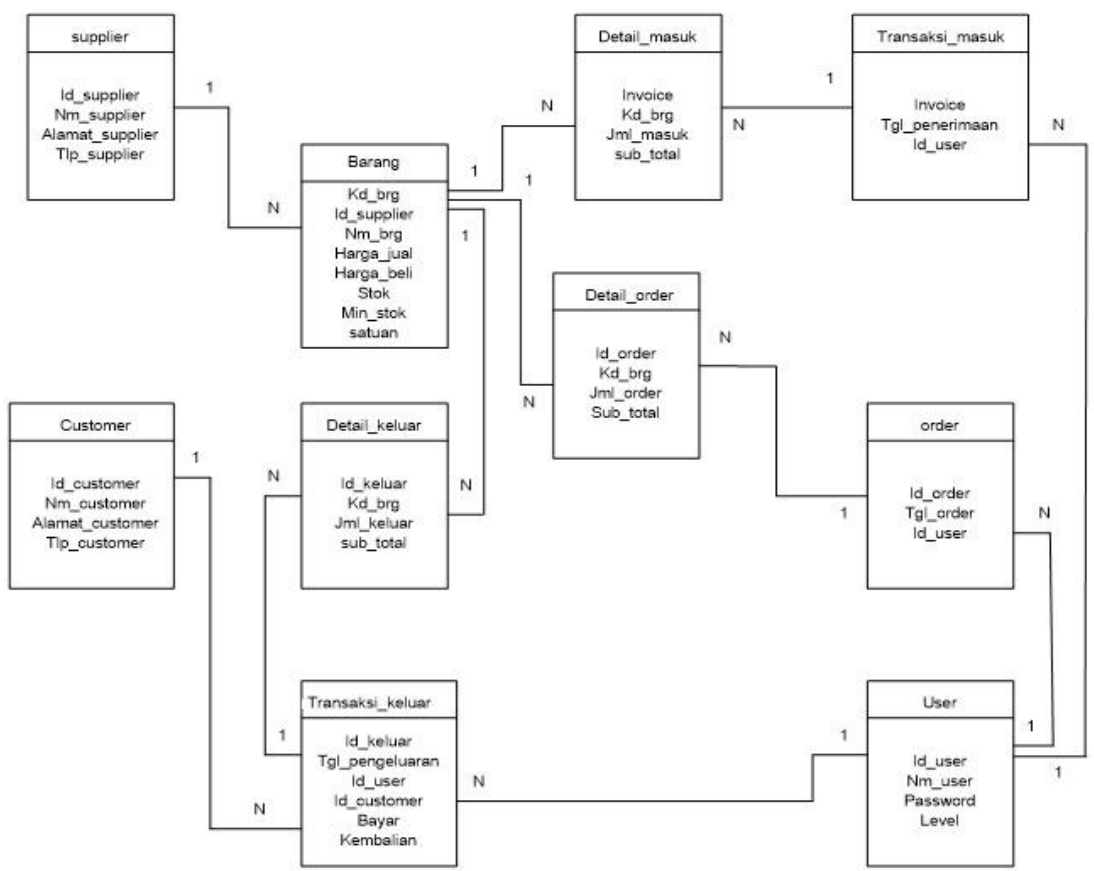

Sumber: Hasil Penelitian (2020)

Gambar 2. Logical Structure Record (LRS) 
Setelah perancangan basis data selesai dibuat, selanjutnya adalah perancangan antarmuka dalam bentuk implementasi tampilan yang terdiri dati:

a. Halaman Login

Pengguna harus login terlebih dahulu untuk dapat mengguanakan program dengan memasukkan kode user dan password dengan benar.

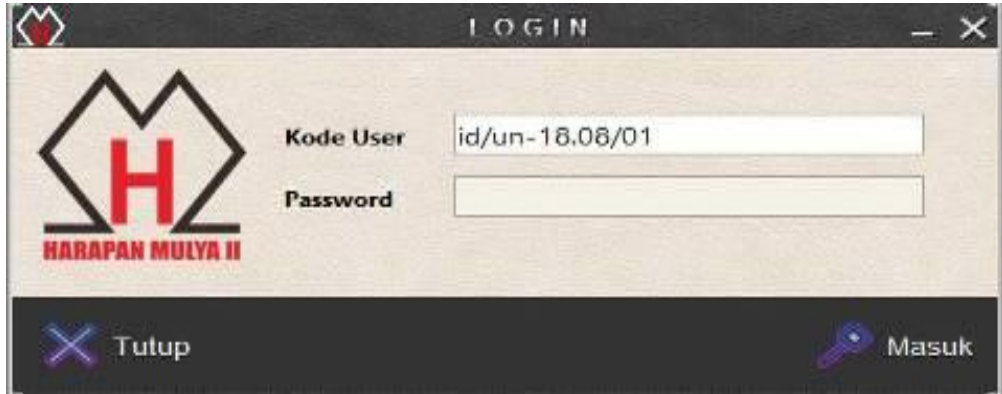

Sumber: Hasil Penelitian (2020)

Gambar 3. Implementasi Halaman Login

b. Halaman Menu Utama

Berisi menu-menu yang bisa diakses oleh pengguna, seperti file, master, transaksi, data dan laporan.

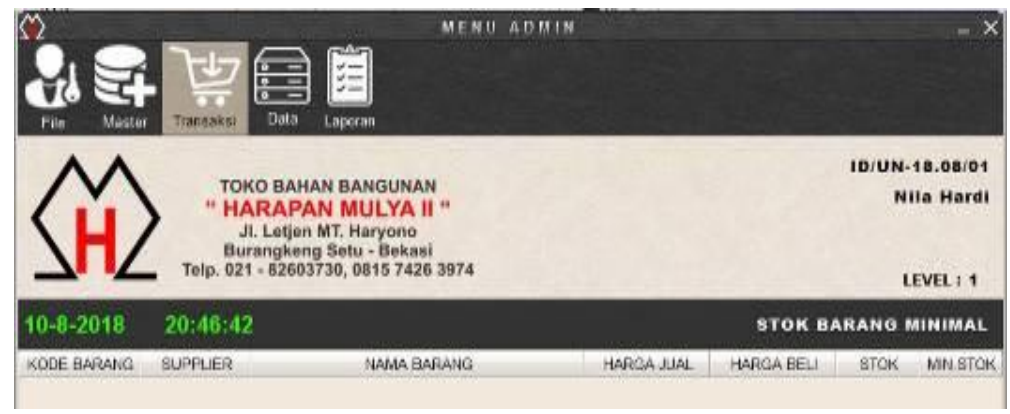

Sumber: Hasil Penelitian (2020)

Gambar 4. Implementasi Halaman Menu Utama

C. Halaman Ganti Password

Halaman yang digunakan oleh pengguna untuk mengubah password, dimana pengguna memasukkan password lama lalu memasukkan password baru dan konfirmasi untuk password baru.

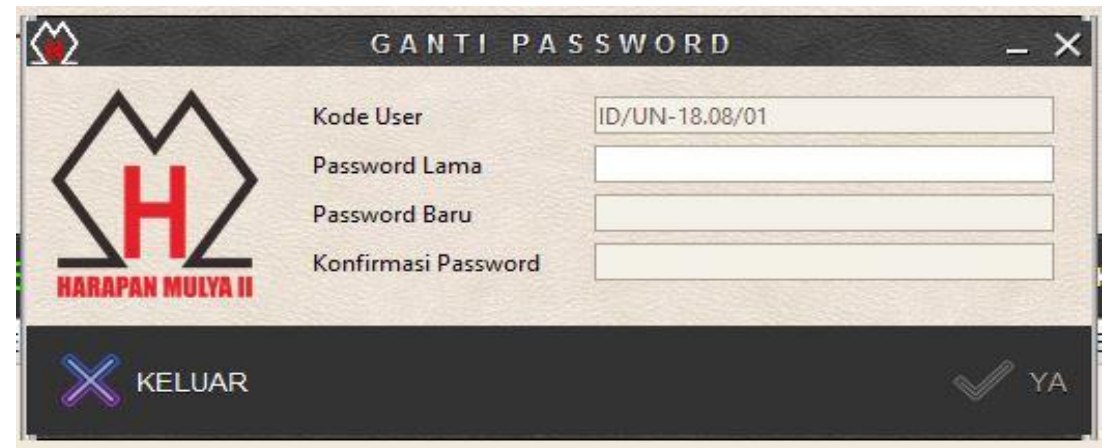

Sumber: Hasil Penelitian (2020)

Gambar 5. Implementasi Halaman Ganti Password 
d. Halaman Master Barang

Halaman yang di gunakan untuk mengelola data barang dengan memasukkan beberapa form inputan.

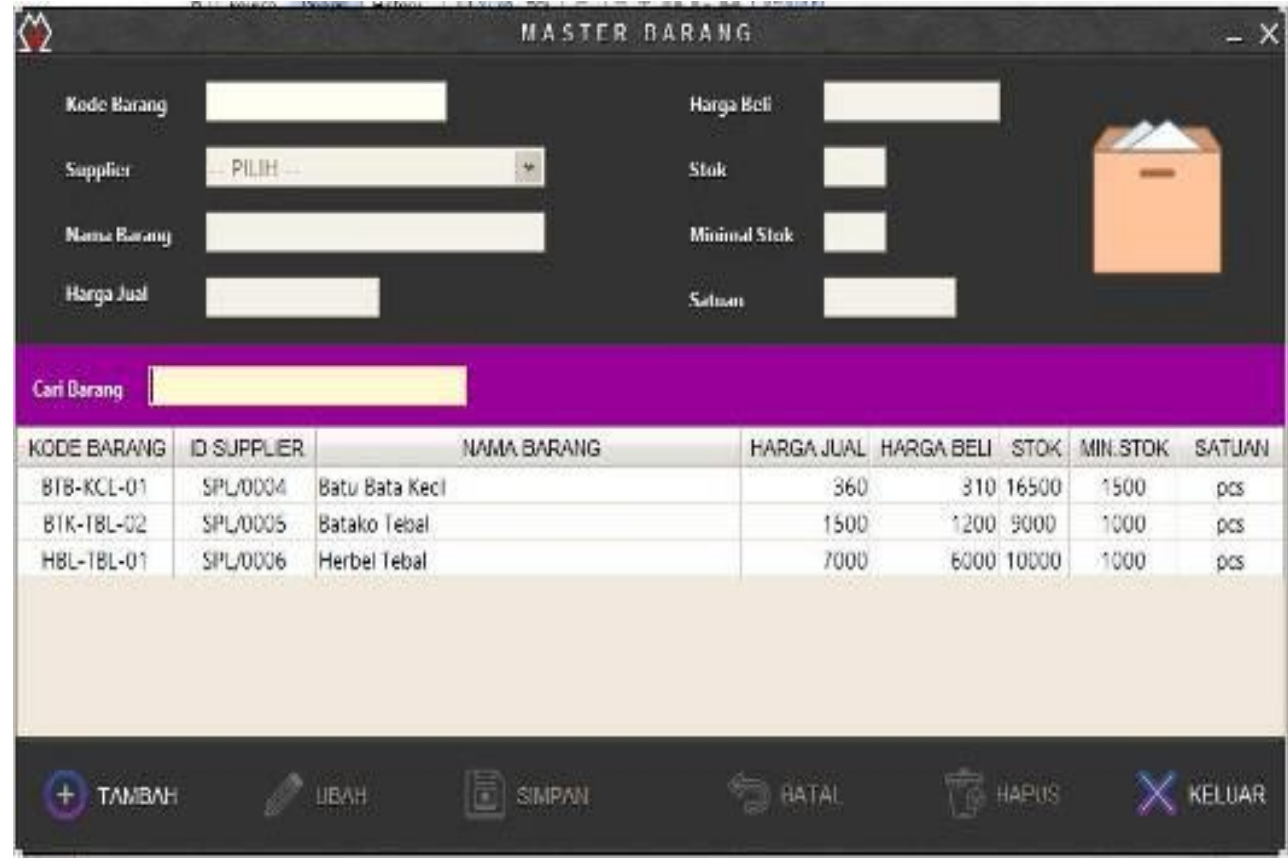

Sumber: Hasil Penelitian (2020)

Gambar 6. Implementasi Halaman Master Barang

e. Halaman Transaksi Order

Halaman yang digunakan untuk mengelola data order barang dengan memasukkan kode barang dan jumlah barang sehingga diketahui total order.

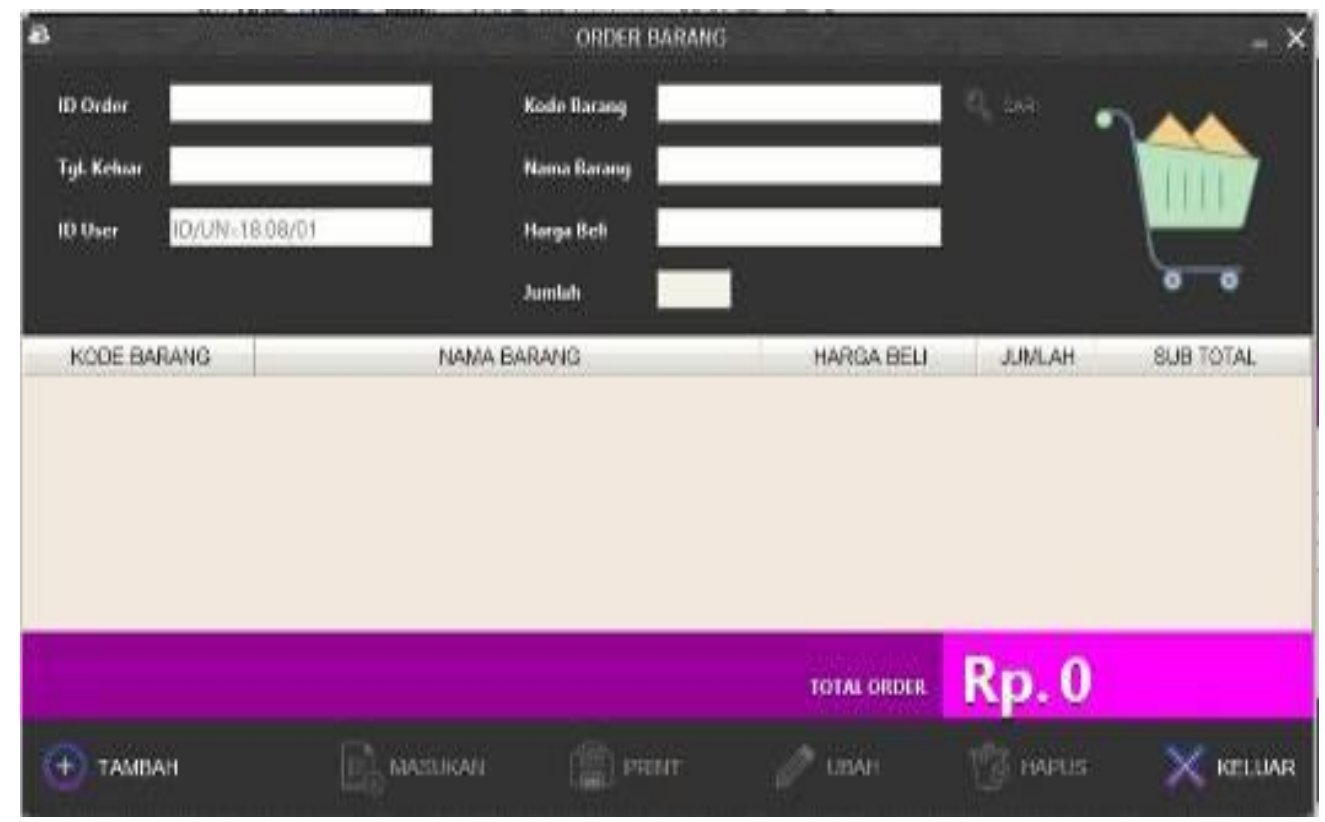

Sumber: Hasil Penelitian (2020)

Gambar 7. Implementasi Halaman Transaksi Order 
f. Halaman Laporan Barang

Halaman yang berisi laporan data-data barang yang telah dilakukan pemesanan.



Sumber: Hasil Penelitian (2020)

Gambar 8. Implementasi Halaman laporan barang

\section{Kesimpulan}

Berdasarkan penjelasan yang telah disampaikan di bagian hasil dan pembahasan, beberapa kesimpulan dapat ditulis, yaitu 1) Dengan adanya Program persedian barang pada TB. Harapan Mulya II dapat mempermudah proses pengolahan data barang, user, customer, supplier, transaksi order barang, transaksi barang masuk serta transaksi barang keluar. 2) Waktu kerja menjadi lebih efisien, kecepatan dalam pengolahan data dan pencarian datapun menjadi lebih cepat sebagaimana yang telah dirancang oleh penulis. 3) Adanya progam ini juga dapat mempermudah pengguna dalam melakukan pengecekan stok barang yang tersedia di TB Harapan Mulya II.

\section{Daftar Pustaka}

Enterprise, J. (2017). Java Komplet. PT. Elex Media Komputindo.

Haqi, B. (2017). Membuat Aplikasi Antrean Dengan Java Netbeans IDE 8.0.2 Dan Database MySQL. PT. Elex Media Komputindo.

Hariyanto, B. (2014). Esensi-Esensi Bahasa Pemrograman Java. Informatika Bandung.

Rahayu, S., Kariman, A., \& others. (2016). Pengembangan Sistem Informasi Persediaan Dan Penjualan Barang Di Perusahaan Dagang Dodol Juwita Garut Berbasis Dekstop. Jurnal Algoritma, 13(1), 205-210.

Rosidin, \& Lubis, B. O. (2017). Implementasi Program Persediaan Barang pada CV. Ardho Teknik Bekasi. 2, 172-180.

Sukamto, R. A., \& Shalahuddin, M. (2015). rekayasa perangkat lunak. Informatika. 